J. Environ. Sci.

Institute of Environmental Studies and Research - Ain Shams University

\title{
MANAGEMENT OF ASTHMA-COPD OVERLAP SYNDROME: CLINICAL PHARMACIST PERSPECTIVE.
}

Farrag, Rana, R. ${ }^{(1)}$; Zaki, M. A. ${ }^{(2)}$ and El-Naggar, T. ${ }^{(3)}$

1) Clinical Pharmacy, Mansheyat El Bakry General Hospital, Minisrty of Health and Population 2) Department of Clinical Pharmacy, Faculty of Pharmacy, Ahram Canadian University 3) Department of Chest Diseases, Faculty of Medicine, Ain Shams University

\begin{abstract}
Introduction: Patients with asthma-COPD overlap have more severe symptoms than those with either asthma or COPD alone, experiencing more frequent and more severe exacerbations and more frequent hospitalizations. This relatively recent interim disease has several phenotypes and consequently different prevalence which ranged from $12 \%-55 \%$ of patients with chronic obstructive airway diseases. Appropriate Asthma-COPD overlap diagnosis and management are needed to achieve control of such progressive disease.

Objective: The study compares the effect of Asthma-COPD overlap patient care by clinical pharmacist intervention versus conventional care on disease control.
\end{abstract}

Patients and Methods: A 2-month ethically approved randomized, controlled trial was conducted in outpatient clinics of Ain Shams University Hospitals, Cairo, Egypt. Patients signed information consents then they were randomly assigned to receive conventional care $(n=28)$ or a pre-defined pharmacist intervention $(n=26)$. This intervention mainly focused on patient education, improving inhalation technique and medication assessment. Primary outcome was the level of disease control, as assessed by the COPD Assessment Test (CAT).

Results \& Discussion: By the end of the study, the patients who received a clinical pharmacist education and medication assessment (intervention group) showed significantly improved outcome regarding their CAT-scores than routine care group who did not receive clinical pharmacist intervention $(\mathrm{p}=0.0001)$. The intervention also reduced reliever medication use. Inhalation 
technique and adherence to medication were significantly better in the intervention group. Patients in the intervention group experienced less exacerbations with decreased need for emergency department visits and/ hospitalization than conventional care patients despite similar doses of corticosteroids in both groups. This suggests that the improvement in symptom control seen in the intervention group can be attributed to beneficial patient education and not to changes in pharmacotherapy.

Conclusion: The present study results provide supportive evidence concerning clinical pharmacists' favorable effects on asthma-COPD overlap patient care and support clinical pharmacists as members of the health care team.

\section{INTRODUCTION}

Patients with asthma-COPD overlap have more severe symptoms than those with either asthma or COPD alone, experiencing more frequent and more severe exacerbations and more frequent hospitalizations. This relatively recent interim disease has several phenotypes and consequently different prevalence ranged from $12 \%$ - 55\% of patients of chronic obstructive airway diseases. Despite the considerable prevalence of Asthma-COPD Overlap, few randomized controlled trials have been performed in patients with ACO and a clear management approach is not yet established for ACO (Ding and Small, 2017).

\section{The goals of therapy of ACOS as a distinct clinical phenotype of COPD} are:

1. Relieve symptoms and improve Quality of life (QOL)

2. Improve pulmonary functions and bronchial hyperreactivity

3. Improve and maintain exercise tolerance and physical activities

4. Prevent disease progression and airway remodeling

\section{Prevent exacerbation}


6. Prevent and treat complications and comorbidities

7. Reduce mortality

8. Prevent adverse effects by therapeutic agent (Kondo and Tamaoki, 2017)

In an attempt to improve Asthma-COPD overlap control, the Global Initiative for Asthma updated its recommendations for initial treatment for clinical efficacy and safety as follows:

For patients with features of asthma indicative of chronic airway inflammation: history of respiratory symptoms such as wheeze, shortness of breath, chest tightness and cough that vary over time and in intensity, together with variable expiratory airflow limitation. Medical management depends on prescribing adequate controller therapy including inhaled corticosteroids (ICS), but not long-acting bronchodilators alone (as monotherapy). (GINA, 2015)

For patients with features of COPD based on a postbronchodilator FEV1/forced vital capacity ratio of less than either 0.70 or the lower limit of normal.and some distinctive clinical phenotypes including chronic bronchitis and/or emphysema. Medical management depends on prescribing appropriate symptomatic treatment with bronchodilators or combination therapy, but not ICS alone (as monotherapy). (Reddel, 2015 and GOLD, 2018).

For ACO treat with ICS in a low or moderate dose (depending on level of symptoms); add on treatment with long-acting $\beta 2$ agonist (LABA) and/ or long-acting muscarinic antagonist (LAMA) is usually also necessary. If there are features of asthma avoid LABA monotherapy; all patients with chronic airflow limitation should receive appropriate treatment for other clinical 
problems including advice about smoking cessation, physical activity and treatment of comorbidities.

Non-pharmacological therapeutic modalities include smoking cessation, treatment of comorbid conditions, physical activity, pulmonary rehabilitation, vaccinations, selfmanagement (including a regularly updated action plan) and regular follow-up. Treatment of patients with asthma-COPD overlap involves long-term inhaled corticosteroid (ICS) treatment to reduce the risk of asthma flare-ups. Most patients should also have a trial of a long-acting beta2 agonist (LABA) and/or long-acting muscarinic antagonist (LAMA). The use of LABAs or LAMAs without concomitant ICS should be avoided in patients with any features of asthma, or a history of asthma, because this increases the risk of hospitalisation and death. Management also includes treatment of comorbid conditions. (Bourbea, et al., 2017)

The development of Asthma-COPD Overlap syndrome is mainly contributed to patient's susceptibility (host factors) and exposure (environmental factors). "Figure 1" (Reddel, 2015). Host factors such as hyperresponsiveness, family history of asthma, and low lung function are common risk factors for asthma and COPD. Environmental tobacco smoke and air pollution are environmental factors of increased interest. 
J. Environ. Sci.

Institute of Environmental Studies and Research - Ain Shams University

\section{SUSCEPTIBILITY \\ FACTORS}

Genetics

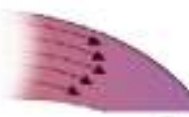

SPECIFIC MOLECULAR

MECHANISMS

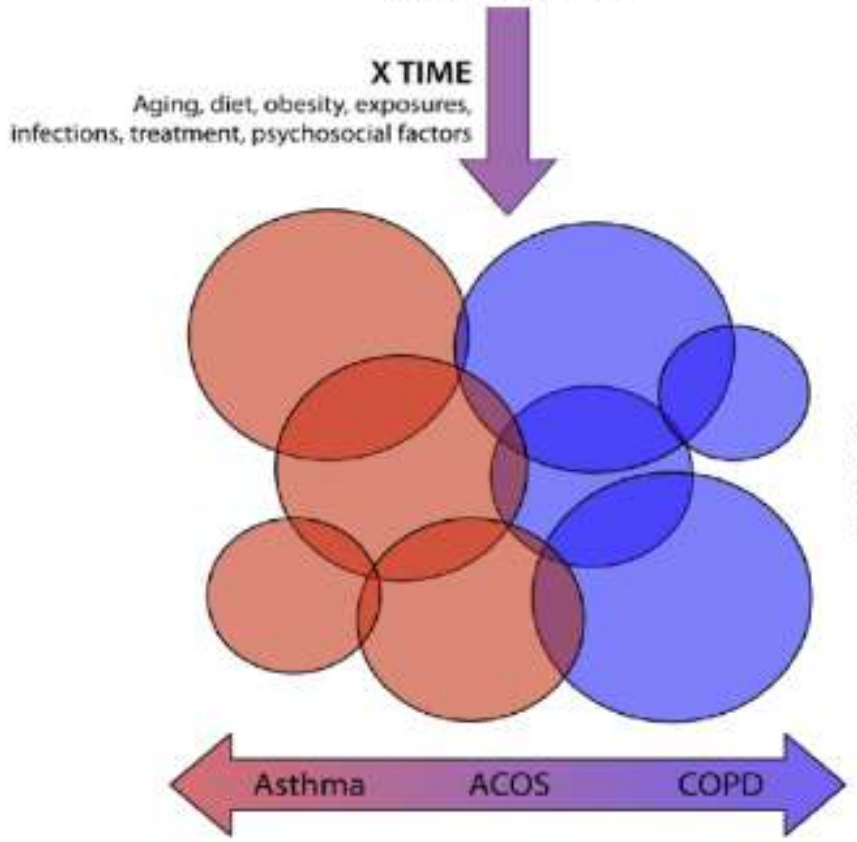

ENVIRONMENT

Smoking.

biomass exposure

pollution, infections

microbiome, diet
CLINICAL PHENOTYPES

Symptoms, physiology.

biomarkers

Figure (1): Schematic for development of asthma, COPD, and ACOS (Reddel, 2015).

Together, a patient's susceptibility (genetic makeup) and exposures (including smoking, infections, pollutants, and diet) contribute to the development of specific molecular or pathologic disease pathways. These interact overtime with the effects of aging, exposures, infections, treatments, and psychosocial factors to produce a range of overlapping clinical phenotypes, which are identified by differing symptoms, physiologic features, and/or biomarkers. At present, we classify these collectively by the terms 
asthma, COPD, and ACOS; each term represents a heterogeneous collection of conditions expected to have different underlying mechanisms rather than representing a continuum within a single disease. Studying disease processes before the effects of aging and treatment are superimposed would improve the chance of identifying specific modifiable pathways.

The environmental protection agency (EPA) has identified six pollutants as "criteria" air pollutants because it regulates them by developing sciencebased guidelines for setting permissible levels. These six pollutants are carbon monoxide, lead, nitrogen oxides, ground-level ozone, particle pollution (often referred to as particulate matter), and sulfur oxides. Recently, two types of air pollutants have attained increased concern: ozone and particle pollution. Climate change creates conditions, including heat and stagnant air, which increase the risk of unhealthful ozone levels exaggerating the effect of Ground-level Ozone Pollution (EEAA, 2015).

Particulate air pollution is a complex mixture of solid particles and liquid droplets of different size, composition, and origin suspended in the air. Particles with a diameter less than $10 \mu \mathrm{m}$ in aerodynamic diameter are referred to as PM10 and are of special interest because they are inhalable. Studies on the association between hospital admission and PM10 pollution have shown that PM10 plays a role in the incidence and severity of respiratory disease. PM10 is divided into coarse fraction $(>2.5 \mu \mathrm{m}$ in diameter), which are retained in the upper airways of the respiratory tract and a finer fraction $(<2.5 \mu \mathrm{m}$ in diameter), which is also referred to as PM2.5. These finer fractions are able to penetrate deep into the respiratory tract and significantly correlated with deaths from cardiopulmonary disease and lung 
cancer. Different sources contribute to increased particulate matter levels. Fuel combustion processes in transportation and energy production are the primary sources of the outdoor PM2.5, whereas cooking, smoking, and cleaning activities contribute primarily to the indoor PM2.5 levels. The indoor particulates originate from both indoor and outdoor sources such as traffic-related fine particles penetrating into indoor environments (AbdelSalam, 2013). Patient education on reducing levels of indoor air pollution is crucial part in management of respiratory diseases.

Clinical pharmacists, as valuable partners in health care team, can play an important role in optimizing Asthma-COPD overlap management through providing adapted pharmacotherapy alongside comprehensive patient education on appropriate medication use and avoidance of airway obstruction triggers including environmental tobacco smoke and air pollutants. Such management approaches have proven to be effective for both asthma and COPD. However, effectiveness of such approaches in patients with AsthmaCOPD overlap is yet to be shown in clinical trials (Gibson and McDonald, 2015). This study compares the effect of Asthma-COPD overlap patient care by clinical pharmacist intervention versus conventional care on disease control.

\section{PATIENTS AND METHODS}

Patients signed written information consents for participating in a 2month ethically approved study was carried out between October 2016 and October 2017 at the outpatient clinics of Ain Shams University Hospitals, Cairo, Egypt (specifically clinic for chest diseases in cooperation with 
immunology department for allergy testing). Patients were randomly assigned to receive conventional care $(n=28)$ or a pre-defined pharmacist intervention $(n=26)$.

\section{Patients were invited to participate in the study provided that they are:}

1. Adult patients with established diagnosis of asthma-COPD overlap syndrome (done by physician as recommended by the Global Initiative for Asthma (GINA) and Global Initiative for Chronic Obstructive Lung Disease (GOLD) guidelines committees, which is "Asthma-COPD overlap syndrome (ACOS) is characterized by persistent airflow limitation with several features usually associated with asthma and several features usually associated with COPD)". We used history of asthma diagnosis and exposure to noxious particles such as environmental tobacco smoke and/or air pollution besides FEV1/forced vital capacity ratio of less than either 0.70 or the lower limit of normal with marked reversibility and readily response to inhaled corticosteroids therapy as distinctive features for ACO.

2. Patients are over 40 years of age

3. Responsible for administering their own medications.

\section{Patients were excluded from the study if they were:}

1. Not responsible for administering their own medications,

2. Suffering from cognitive defects,

3. Unavailable for 2-month follow-up, or

4. Did not provide written informed consent.

At baseline, each patient provided his/her personal information, medical history in patient data record, answered COPD Assessment Test (CAT- score) "Figure 2", and underwent spirometry to measure his/her forced expiratory 
volume in 1 second (FEV1). Patients in the intervention group received a protocol-defined intervention at the start of the study and lasted over a 2month follow-up period while patients in the conventional care group received usual care as an active comparator. Patients in the pharmacistintervention group received additional education by the clinical pharmacist on basic facts about asthma-COPD overlap syndrome, role of medications, the difference between long-term control medications and quick-relief medication, as well as patient skills in establishing proper inhalation technique on his own inhalation device in the first visit then reinforcement every two weeks. Proper inhaler technique and avoidance of airway obstruction triggers including environmental tobacco smoke and air pollutants were highlighted as vital part of patient education. Proper inhaler technique was physically demonstrated to the patient and the patient was asked to return the demonstration on his/her own device. Assessment of inhaler technique was repeated at each follow-up visit using proper inhaler technique checklist to pinpoint incorrect steps and subsequently correct them "Figure 3". Also, patient concerns about medications and their clinical status were addressed to facilitate adherence. Patients were informed how to detect early signs of worsening airflow limitation, when and how to seek medical care as appropriate. 


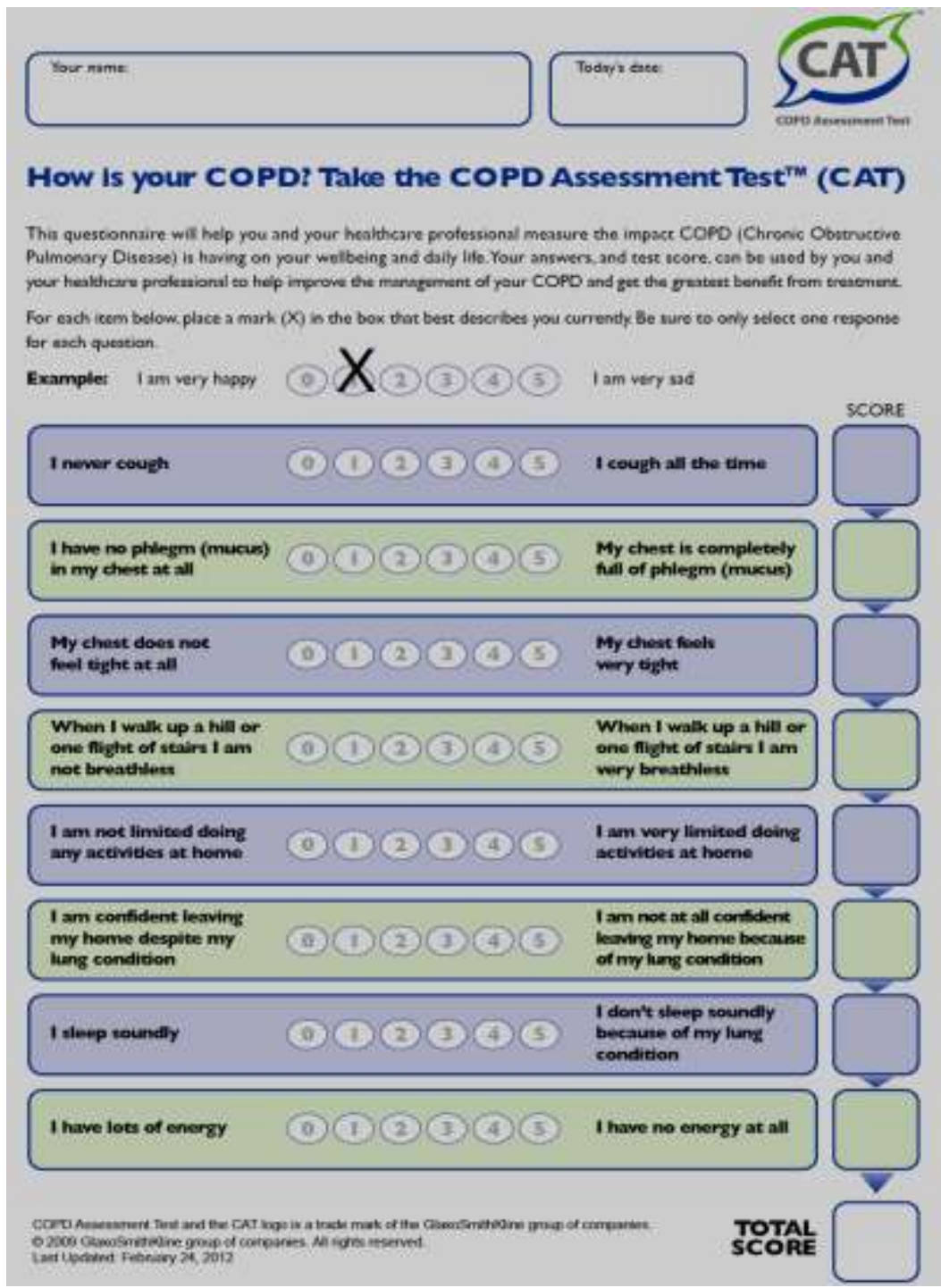

Figure (2): COPD Assessment Test 
J. Environ. Sci.

Institute of Environmental Studies and Research - Ain Shams University

\section{Proper Inhalation Technique Checklist for Metered Dose} Inhaler

1. Remove the cap from the MDI and shake well.

2. Breathe out all the way.

3. Place the mouthpiece of the inhaler between your teeth and seal your lips tightly around it.

4. As you start to breathe in slowly, press down on the canister one time.

5. Keep breathing in as slowly and deeply as you can. (It should take about 5 to 7 seconds for you to completely breathe in.)

6. Hold your breath for 10 seconds (count to 10 slowly) to allow the medication to reach the airways of the lung.

7. Repeat the above steps for each puff ordered by your doctor. Wait about 1 minute between puffs.

8. Replace the cap on the MDI when finished.

Figure (3): Proper Inhalation Technique Checklist for Metered Dose Inhaler (Cleveland_clinic, 2014).

Patients in the conventional care group received medical care provided by physician without clinical pharmacist intervention. At the stated setting (Ain Shams University Hospitals), most physicians recommend chest x- ray and spirometry once at early diagnosis to rule-out other causes of pulmonary obstruction. They prescribe quick-relief medication and another long-term control medication according to severity of symptoms (mostly, inhaled corticosteroid and bronchodilator). Spirometry may be performed to explain unmet treatment responses and poor control. Physicians may schedule a follow-up visit one or two months after patient discharge. Follow-up visits were not planned on consistent basis, but rather individually according to the disease status. 


\section{RESULTS AND DISCUSSION}

A total of fifty four patients completed the study showing the following results in Tables 1,2 and 3

Table (1): Demographic Characteristics for Patients Participating in the Study.

\begin{tabular}{|c|c|c|c|c|}
\hline Variable & $\begin{array}{l}\text { Intervention } \\
\text { Group } n=26\end{array}$ & $\begin{array}{c}\text { Conventional } \\
\text { Care Group } n=28\end{array}$ & $\begin{array}{c}\mathbf{P}- \\
\text { value }\end{array}$ & $\begin{array}{l}\text { Sig } \\
\cdot\end{array}$ \\
\hline Gender n (\%) a & & & \multirow{3}{*}{0.637} & \multirow{3}{*}{ NS } \\
\hline Male & $7(26.9)$ & $6(21.4)$ & & \\
\hline Female & $19(73.1)$ & $22(78.6)$ & & \\
\hline Age (Year) & & & \multirow[b]{2}{*}{0.724} & \multirow[b]{2}{*}{ NS } \\
\hline Mean $\pm \mathrm{SD}($ range $) \mathrm{b}$ & $\begin{array}{c}50.86 \pm 8.75 \\
(40-68)\end{array}$ & $\begin{array}{c}46.04 \pm 6.83 \\
(40-63)\end{array}$ & & \\
\hline Education n (\%)a & & & \multirow{4}{*}{0.927} & \multirow{4}{*}{ NS } \\
\hline No High School Degree & $11(42.3)$ & $13(46.4)$ & & \\
\hline High School Degree & $13(50)$ & $11(39.3)$ & & \\
\hline Higher Education\$ & $2(7.7)$ & $4(14.3)$ & & \\
\hline Smoking Status a & & & & \multirow{4}{*}{ NS } \\
\hline Non-Smoker & $17(65.4)$ & $20(71.4)$ & \multirow{3}{*}{0.878} & \\
\hline Active Smoker & $6(23.1)$ & $5(17.9)$ & & \\
\hline Passive Smoker & $3(11.5)$ & $3(10.7)$ & & \\
\hline \multicolumn{4}{|l|}{$\begin{array}{c}\text { Co-morbid Conditions: } \\
\text { n }(\%) \mathbf{a} \\
\end{array}$} & \multirow{5}{*}{ NS } \\
\hline Hypertension & $3(11.5)$ & $2(7.1)$ & \multirow{4}{*}{$\begin{array}{c}0.660 \\
(\chi 2= \\
1.596)\end{array}$} & \\
\hline Diabetes & $3(11.5)$ & $3(10.7)$ & & \\
\hline Sinusitis & $2(7.7)$ & $1(3.6)$ & & \\
\hline Obesity & $13(50)$ & $4(14.3)$ & & \\
\hline
\end{tabular}

Data are expressed as n (\%) or mean (range) unless otherwise indicated, $\mathrm{N}$ : number; SD: standard deviation, a Chi-Square test at level of significance $p \leq 0.05$, b Independent t-test at level of significance $p \leq 0.05$, Sig.: Statistical Significance, NS: Non-Significant, \$ succeeded any type of higher education (college or university). 
J. Environ. Sci.

Institute of Environmental Studies and Research - Ain Shams University

Table (2): Clinical Characteristics for Patients Participating in the Study at Baseline.

\begin{tabular}{|c|c|c|c|c|}
\hline Variable & $\begin{array}{l}\text { Intervention } \\
\text { Group } n=26\end{array}$ & $\begin{array}{c}\text { Conventional } \\
\text { Care Group } \\
n=28 \\
\end{array}$ & $\begin{array}{c}\text { P- } \\
\text { value }\end{array}$ & Sig \\
\hline CAT-score & $27.04 \pm 7.55$ & $26.68 \pm 6.96$ & 0.979 & NS \\
\hline mean $\pm \mathrm{SD}($ range $) \mathrm{a}$ & $(9-38)$ & $(28-40)$ & & \\
\hline FEV1/FVC & $0.65 \pm 0.04$ & $0.65 \pm 0.07$ & 0.696 & NS \\
\hline mean $\pm \mathrm{SD}($ range $) \mathrm{a}$ & $(0.58-0.69)$ & $(0.29-0.7)$ & & \\
\hline FEV1\% predicted normal & $67.73 \pm 15.41$ & $63.82 \pm 18.05$ & 0.398 & NS \\
\hline mean $\pm \mathrm{SD}$ (range)a & $(26-88)$ & $(31-88)$ & & \\
\hline Rescue medication SABA & 4.1 & 4.9 & 0.772 & NS \\
\hline $\begin{array}{l}\text { average number of puffs used } \\
\text { most days geometric mean } \\
\text { (range)b }\end{array}$ & $(0-18)$ & $(0-18)$ & & \\
\hline Mean daily dose of ICS & 6.65 & 4.96 & 0.173 & NS \\
\hline $\begin{array}{l}\text { average puffs of beclomethasone } \\
\text { equivalent to } 50 \mathrm{mcg} / \text { puff } \\
\text { (range) } \mathrm{b}\end{array}$ & $(2-12)$ & $(0-18)$ & & \\
\hline \multicolumn{5}{|l|}{ Inhalation Technique:* } \\
\hline$\%$ Correct Steps (mean \pm SD) a & $69.23 \pm 23.25$ & $68.06 \pm 24.35$ & 0.858 & NS \\
\hline Patients Scoring $100 \%$ b & 3.8 & 7 & & \\
\hline Patients Scoring 0\% b & 3.8 & 3 & 0.709 & NS \\
\hline
\end{tabular}

Data are expressed as n (\%) or mean (range) unless otherwise indicated. $\mathrm{N}$ : number, SD: standard deviation. a Independent t-test at level of significance $p \leq 0.05$, b Chi-Square test at level of significance $p \leq 0.05$; Sig. Statistical Significance, S: Significant, NS: Non-Significant. CAT: COPD Assessment Test, FEV1: Forced Expiratory Volume in 1second, FVC: Forced Vital Capacity, SABA: Short-Acting Beta2 Agonist, ICS: Inhaled Corticosteroid, LABA: Long-Acting Beta2 Agonist. *Inhalation technique 
was scored proper inhaler technique checklist to pinpoint incorrect steps and subsequently correct them. For each correct step, one point was assigned and the sum score was displayed as percentage of correct steps. Patients committing major errors in inhalation technique (failure to remove cap and/or fail to shake MDI) were assigned a sum score of zero.

Table (3): Clinical Characteristics for Patients at the end of the Study.

\begin{tabular}{|c|c|c|c|c|}
\hline Variable & $\begin{array}{c}\text { Interventio } \\
\text { n Group } \\
\text { n=26 }\end{array}$ & $\begin{array}{c}\text { Conventional } \\
\text { Care Group } \\
\mathbf{n}=\mathbf{2 8}\end{array}$ & $\begin{array}{c}\text { P- } \\
\text { value }\end{array}$ & Sig \\
\hline \multirow{2}{*}{ CAT-score mean \pm SD (range) a } & $8.27 \pm 5.75$ & $18.36 \pm 6.08$ & 0.0001 & $\mathrm{~S}$ \\
\hline & $(3-32)$ & $(8-32)$ & & \\
\hline \multirow{2}{*}{$\begin{array}{c}\text { FEV1/FVC mean } \pm \text { SD (range) } \\
\text { a }\end{array}$} & $0.81 \pm 0.1$ & $0.79 \pm 0.11$ & 0.547 & NS \\
\hline & $(0.53-0.97)$ & $(0.4-0.96)$ & & \\
\hline \multirow{2}{*}{$\begin{array}{l}\text { FEV1\% predicted normal } \\
\text { mean } \pm \text { SD (range) a }\end{array}$} & $83.31 \pm 18.16$ & $72.14 \pm 20.06$ & 0.0372 & $\mathrm{~S}$ \\
\hline & $(45-100)$ & $(23-100)$ & & \\
\hline Rescue medication SABA & \multirow[b]{2}{*}{$1.038(0-6)$} & \multirow[b]{2}{*}{$3.39(0-8)$} & \multirow[b]{2}{*}{0.0001} & \multirow[b]{2}{*}{$\mathrm{S}$} \\
\hline $\begin{array}{l}\text { average number of puffs used most days: } \\
\text { geometric mean (range)b }\end{array}$ & & & & \\
\hline Mean daily dose of ICS & \multirow[b]{2}{*}{$4.46(2-6)$} & \multirow[b]{2}{*}{$4.57(0-8)$} & \multirow[b]{2}{*}{0.769} & \multirow[b]{2}{*}{ NS } \\
\hline $\begin{array}{l}\text { average puffs of beclomethasone } \\
\text { equivalent to } 50 \mathrm{mcg} / \text { puff (range) b }\end{array}$ & & & & \\
\hline ER Visits \& Hospitalization $\leq 2$ days: & \multirow{2}{*}{$0.269(0-1)$} & \multirow{2}{*}{$0.714(0-3)$} & \multirow{2}{*}{0.042} & \multirow{2}{*}{$\mathrm{S}$} \\
\hline geometric mean (range)b & & & & \\
\hline $\begin{array}{c}\text { Number of Courses of Systemic } \\
\text { Steroid Used*: }\end{array}$ & \multirow[t]{2}{*}{$0.423(0-2)$} & \multirow[t]{2}{*}{$0.73(0-3)$} & \multirow[t]{2}{*}{0.326} & \multirow[t]{2}{*}{ NS } \\
\hline geometric mean (range)b & & & & \\
\hline \multicolumn{5}{|l|}{ Inhalation Technique:** } \\
\hline$\%$ Correct Steps mean \pm SD a & $91.83 \pm 9.96$ & $76.85 \pm 21.00$ & 0.0018 & $\mathrm{~S}$ \\
\hline PatientsScoring $100 \% \mathrm{~b}$ & 54 & 7 & & \\
\hline Patients Scoring 0\%b & 0 & 3 & 0.0005 & $\mathrm{~S}$ \\
\hline \multicolumn{5}{|l|}{$\begin{array}{l}\text { Patient Adherence to medication (n } \\
\qquad \%) \mathbf{b}^{* * *}\end{array}$} \\
\hline Adherent & 90 & 66.7 & & \\
\hline Non-adherent & 10 & 33.3 & 0.028 & $\mathrm{~S}$ \\
\hline
\end{tabular}


Data are expressed as n (\%) or mean (range) unless otherwise indicated. $\mathrm{N}$ : number, SD: standard deviation. a Independent t-test at level of significance $p \leq 0.05$; $b$ Chi-Square test at level of significance $p \leq 0.05$; Sig. Statistical Significance; S: Significant; NS: Non-Significant. CAT: COPD Assessment Test; FEV1: Forced Expiratory Volume in 1second; FVC: Forced Vital Capacity, SABA: Short-Acting Beta2 Agonist, ICS: Inhaled Corticosteroid in the form of beclomethasone-salbutamol combination metered-dose inhalers according to availability and price affordability; ER: Emergency Room; * Courses of Systemic Steroid Used are expressed as number of courses used rather than dosage, each course is represented by starting dose of prednisolone $37.5-50 \mathrm{mg}$, then repeat each morning on second and subsequent days (total 5-10 days according to severity of exacerbation). **Inhalation technique was scored proper inhaler technique checklist to pinpoint incorrect steps and subsequently correct them. For each correct step, one point was assigned and the sum score was displayed as percentage of correct steps. Patients committing major errors in inhalation technique (failure to remove cap and/or fail to shake MDI) were assigned a sum score of zero; ***patient adherence was assed based on prescription refill rate then patients were categorized as adherent $(\geq 65 \%)$ or non-adherent to medication $(<65 \%)$.

In the current study, the pharmacist intervention was tailored to the patient's current control state of Asthma-COPD overlap (ACO). By the end of the study, intervention group patients who received clinical pharmacist intervention significantly improved their COPD Assessment Test scores (CAT-score) results than conventional care group. The clinical pharmacist 
intervention patients significantly improved both the inhalation technique and medication adherence, which are both key stones for successful ACO management. Together with reduced use of reliever medication, it seems likely that these clinical improvements result from the more appropriate use of the controller medication. Further assessment of inhalation technique steps showed that the most common errors encountered at baseline were incomplete breath-out all the way, failure to hold breath for 10 seconds after inhalation and repeated inhalation steps for multiple puffs without wait 1minute in-between. These errors were significantly reduced in the pharmacist intervention group where patients showed better outcomes.

In the present study, almost all patients were prescribed inhaled corticosteroids as controller treatment in the form of beclomethasonesalbutamol combination metered-dose inhalers according to availability and price affordability.

Patients in the intervention arm were $20 \%$ more adherent than patients receiving conventional care, suggesting a beneficial impact intervention.

Regarding controller medication use, both inhaled and systemic corticosteroid showed no significant difference between the intervention and conventional care groups. However, intervention patients experience less exacerbations with decreased need for emergency department visits and/ hospitalization than conventional care patients. This suggests that the improvement in symptom control seen in the intervention group can be attributed to beneficial patient education and not to changes in pharmacotherapy. 
J. Environ. Sci.

Institute of Environmental Studies and Research - Ain Shams University

\section{CONCLUSION}

The present study results provide supportive evidence concerning pharmacists' favorable effects on asthma-COPD overlap patient care as evident by improvement in COPD Assessment test (CAT) scores, improved inhalation technique and increased medication adherence. The study results support pharmacists as key members of the health care team.

Study Limitations: The present study has its limitations. First, the number of patients participated in the study was relatively small compared to other large multicenter studies investigating asthma care programs. However, this can be explained by time constraints and expression of interim phases of asthma-COPD overlap syndrome.

$\underline{\text { Second, }}$ patients participated voluntarily in the study. Therefore, the selected sample may reflect those patients with a stronger interest in adherence to Asthma-COPD care, possibly generating a positive selection bias.

Third, the present study was an open-label study as the intervention necessitates patient education.

Fourth, patients were prescribed salbutamol and beclomethasone inhalers according to availability and price affordability. Unfortunately, combination inhalers with LAMA and/ or LABA were not available in the study setting.

$\underline{\text { Fifth }}$, the sustainability of beneficial outcomes beyond two months was not assessed.

Recommendations: The present study supports additive evidence for the effectiveness of the clinical pharmacist's contribution in the care of patients with asthma-COPD overlap (ACO). 
Further research should focus on the cost-effectiveness of such intervention, key implementation issues in different pharmacy practice settings and sustainability of effectiveness of pharmacist intervention over longer follow up periods.

\section{REFERENCES}

Abdel-Salam, M.(2013): Indoor particulate matter in urban residences of Alexandria. Egypt Journal of the Air \& Waste Management Association, Volume 63, pp. 956-962.

Bourbea, J. et al.,(2017): CTS position statement: pharmacotherapy in patients with COPD- An update. Canadian Journal of Respiratory, Critical Care, and Sleep Medicine., 1(4), pp. 222-241.

Cleveland_clinic, (2014): How to use a metered dose inhaler. [Online] Available

at:http://my.clevelandclinic.org/health/drugs_devices_supplement s/hic_How_to_Use_a_Metered_Dose_Inhaler [Accessed October 2016].

Ding, B. \& Small, M., (2017): Treatment trends in patients with asthmaCOPD overlap syndrome in a COPD cohort: findings from a realworld survey. International Journal of Chronic Obstructive Pulmonary Disease, Volume 12, pp. 1753-1763.

EEAA Egyptian environmental affairs agency: Egypt state of the environment 2012 issued 2015 .

Gibson, P. \& McDonald, V., (2015): Asthma-COPD overlap 2015: now we are six. Thorax Published Online First:, Volume 0, pp. 1-9. doi:10.1136/thoraxjnl-2014-206740.

GINA, Updated (2015): Global strategy for asthma management and prevention. [Online] Available at: http://www.ginasthma.org. [Accessed 5 March 2016]. 
Global Initiative for Chronic Obstructive Lung Disease (GOLD), 2018. Global Strategy for the diagnosis, management and prevention of Chronic Obstructive Pulmonary Disease. [Online] Available at: www.goldcopd.org [Accessed 5 March 2018].

Kondo, M. \& Tamaoki, J., (2017): Therapeutic approaches of asthma and COPD overlap. Allergology International, doi: 10.1016/j.alit.2017.09.002.

Reddel, H., (2015): Treatment of overlapping asthma-chronic obstructive pulmonary disease: Can guidelines contribute in an evidence-free zone?. J Allergy Clin Immunol, Volume136, Issue 3, pp. 546 552 .

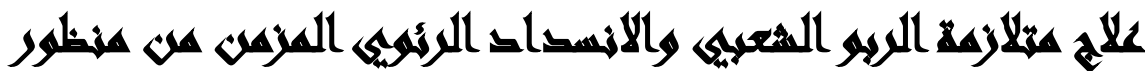

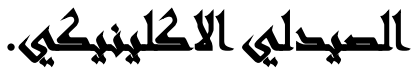

[؛]

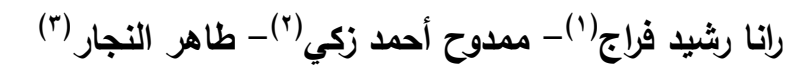

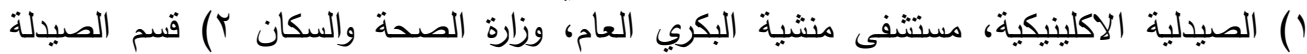
الاكلينيكية، كلية الصيدلة، جامعة الأهرام الكندية r) قسم الأمراض الصندية الصدرية، كلية الطب، جامعة الطان

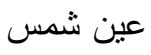

\section{المستخلصى}

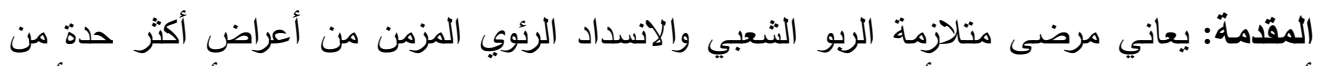

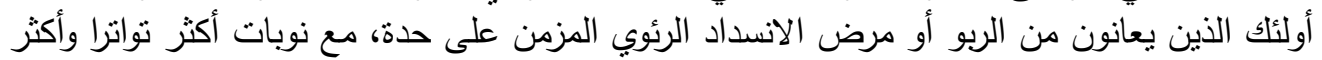

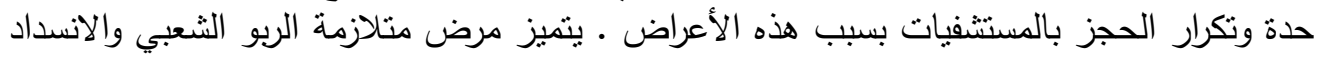

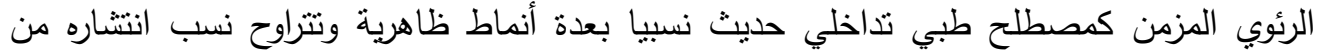

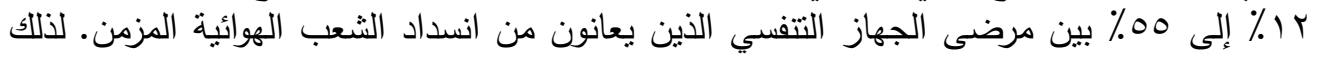

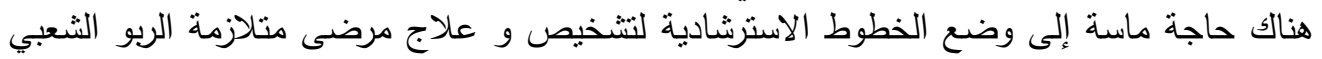

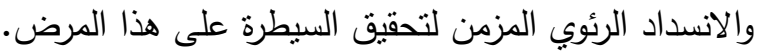

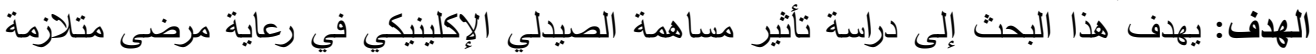

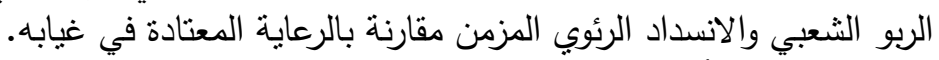

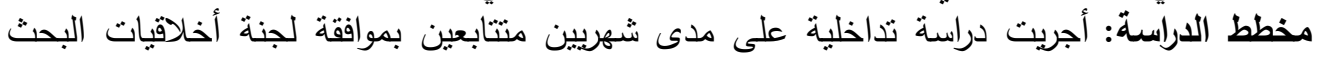

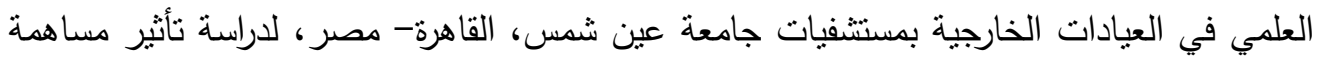


الصيدلي الإكلينيكي في رعاية مرضى متلازمة الربو الثعبي والانسداد الرئوي المزمن مقارنة بالرعاية

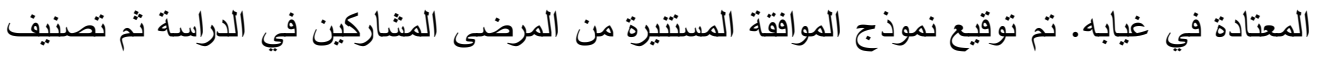

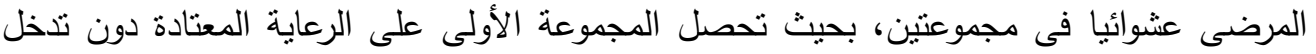

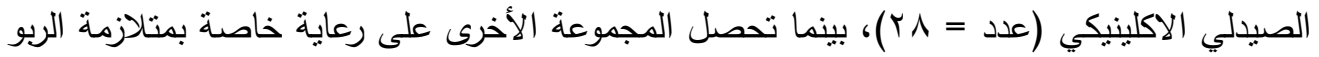

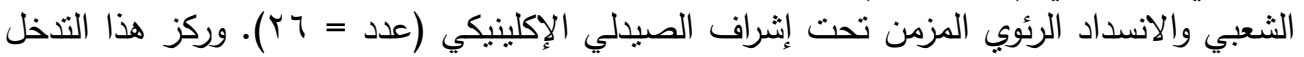

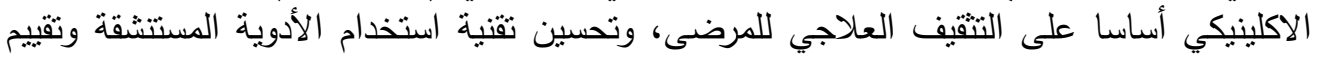

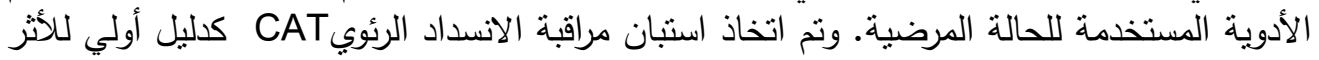

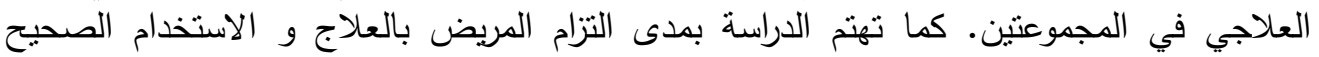
للأدوية المستنشقة كنتائج ثانوية. النتائج والمناقشة: أسفرت النتائج النهائية للاراسة عن تحسن ملحوظ في نتائج استبان مراقبة الانسداد

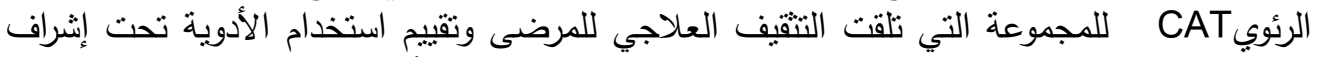

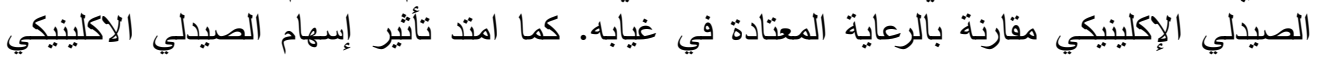

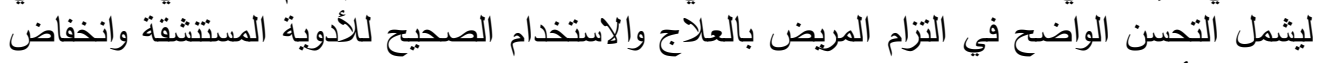

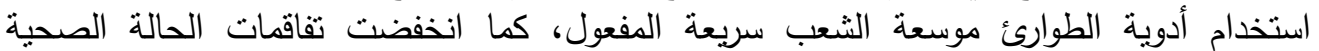

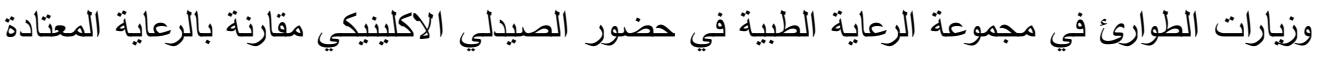

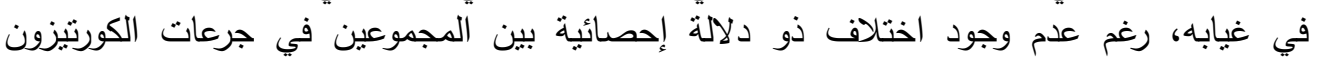

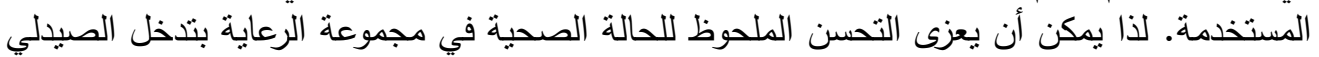

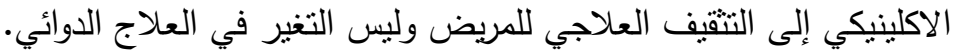

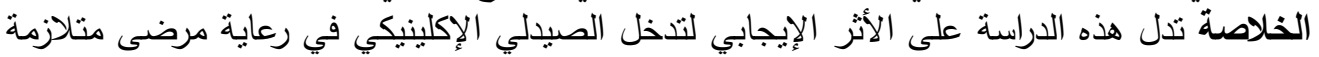

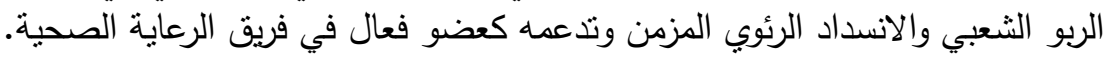

